\title{
Negative priming without reaction time: Effects on identification of masked letters
}

\author{
W. TRAMMELL NEILL and KATHLEEN M. TERRY \\ Adelphi University, Garden City, New York
}

\begin{abstract}
Responses to an object are often slower and/or less accurate if that object is related to a recently ignored object. This negative priming effect has previously been examined only in reaction time tasks. In the present experiment, target letters and flanking distractor letters were displayed for 33 , 100 , or $300 \mathrm{msec}$, followed by a pattern mask. Subjects attempted to identify the target letters, with no demand for speed. Identification accuracy was reduced for targets that matched distractors presented on the immediately preceding trial. However, there was no bias against reporting preceding distractors on catch trials with no presented target. Implications for theories of negative priming are discussed.
\end{abstract}

In speeded reaction time (RT) tasks, responses to an object are often slower if that object is similar to a recently ignored object. For example, in the Stroop (1935) color-word task, color naming is slower if the color corresponds to the immediately preceding distractor word (Dalrymple-Alford \& Budayr, 1966; Lowe, 1979; Neill, 1977). Similar results have since been demonstrated in a wide variety of selective attention tasks (see Neill, Valdes, \& Terry, 1994, for a comprehensive review). Tipper (1985) proposed the term negative priming to describe the inhibitory effects of ignored objects.

In all previously reported experiments on negative priming, subjects have been required to make speeded responses, and RT has been emphasized as the primary dependent variable. Error rates are also often reported to show negative priming (e.g., Neill, 1977; Neill, Terry, \& Valdes, 1994; Neill, Valdes, Terry, \& Gorfein, 1992). In such experiments, the stimuli are typically displayed at high contrast and luminance levels, and they remain visible until the subject's response. Hence, higher error rates on recently ignored stimuli are probably due to hurried incorrect guesses before target processing is complete. The question remains whether negative priming can be demonstrated in error rates without a demand for speeded responses.

Whether negative priming can occur without RT demands is directly relevant to the theoretical conception of negative priming. In RT tasks, negative priming could be caused by delayed stimulus identification, by delayed response selection, or by inhibition of the overt response. In a task emphasizing identification accuracy, with unlimited time to respond, delayed response selection or execution should have minimal effect on performance.

We are grateful to Debra Aurigemma, Ann Eccher, Erina Eccher, Brad Hieger, and Ron Sandoval for their assistance with data collection. Please address correspondence to W. T. Neill, Department of Psychology, Adelphi University, Garden City, NY 11530 (e-mail: neill@sable.adelphi.edu).
Hence, negative priming in such a task would strongly implicate stimulus identification as the locus of the effect.

Several studies indicate that negative priming in RT tasks is not caused by inhibition of an overt response: For example, Tipper, MacQueen, and Brehaut (1988) found negative priming when the preceding ( prime) trial required a verbal response but the current (probe) trial required a manual response, and vice versa. Neill, Lissner, and Beck (1990) used a same/different matching task to manipulate similarity of the probe target to the prime distractor, independently of response similarity. Negative priming occurred regardless of whether prime and probe trials required similar or dissimilar responses.

Other studies suggest that negative priming is not caused by inhibition of perceptual attributes per se: Negative priming occurs between perceptually dissimilar stimuli - for example, between a distractor word and target color in the Stroop task (e.g., Neill, 1977). Similarly, Tipper and Driver (1988) found negative priming between ignored words and target pictures, and vice versa. Such results do not, however, rule out inhibition at more abstract levels of representation, such as semantic category, prior to stimulus identification.

In contrast, some results do argue that negative priming specifically affects response selection: Neill, Valdes, and Terry (1992) found more negative priming in a localization task when subjects were required to make spatially incompatible responses. In a more recent experiment, Neill, Valdes, and Kennedy (1994) found negative priming to occur only when prime and probe trials required the same stimulus-response assignment rules. It is unlikely that stimulus identification would depend on what response is subsequently required. Consequently, Neill et al. (in press) concluded that negative priming is caused by delayed retrieval of the specific stimulusresponse mapping.

In the present experiment, subjects attempted to identify target letters flanked by distractor letters (e.g., $A B A)$. On prime trials, the letters were displayed for ei- 
ther 100 or $300 \mathrm{msec}$, followed by a pattern mask (\#\#\#). After the subject's response, probe trials displayed letters for 33,100 , or $300 \mathrm{msec}$, also followed by a pattern mask. Subjects were instructed to strive for accuracy, and not to rush their responses. Negative priming would be manifested in higher error rates for probe targets that matched the recently ignored prime distractor.

Because subjects were allowed unlimited time to respond, delayed response selection or execution would not directly affect performance in this experiment. However, when uncertain of stimulus identity, subjects might be biased to select a more readily retrievable response, or to avoid the recently avoided response. Thus, negative priming could still be attributed to a response selection process - that is, guessing. In order to control for a guessing bias, the experiment also included "catch" trials, in which the pattern mask, but no target, was presented. If subjects simply guess the recently ignored distractor less often than other possible letters, then "negative priming" should occur even in the absence of an actual target.

\section{METHOD}

\section{Subjects}

The subjects were 29 Adelphi University undergraduates in lower level psychology courses, who participated to satisfy an experiment requirement. All subjects participated in an RT experiment before participating in the present experiment. The first experiment was also concerned with negative priming, but with very different stimulus arrays. Subjects were also not debriefed on the first experiment until after the present one. The total session time was approximately $50 \mathrm{~min}$, with the latter half devoted to the present experiment.

\section{Stimuli and Apparatus}

Stimuli were presented on an AMDEK Color-I Plus video monitor controlled by an Apple Ile microcomputer. The S, C, M, and L keys of the computer keyboard were used to register subjects' responses.

Letter triplets were composed from the capital letters A, B, C, and $D$, drawn from the standard Applesoft character set. A pattern mask consisted of three "pound" signs (\#\#). Letter triplets and pattern masks were centered on the 12th print line of the monitor. At an average viewing distance of $57 \mathrm{~cm}$, the visual angle subsumed by each letter was approximately $.5^{\circ}$ horizontally, and $.8^{\circ}$ vertically. Letter triplets and pattern masks subsumed a total horizontal visual angle of approximately $2.0^{\circ}$.

\section{Procedure}

Subjects used the middle and index finger of each hand to press the $\mathrm{S}, \mathrm{C}, \mathrm{M}$, and $\mathrm{L}$ keys corresponding, from left to right, to the target letters A, B, C, and D. Instructions emphasized that responses should be as accurate as possible, and not be rushed. Subjects were informed that the letters would sometimes be very difficult to see, and that they should give their "best guess" if uncertain. They received one practice block of 20 prime-probe trial pairs, in which stimulus duration was held constant at $300 \mathrm{msec}$. They then received nine experimental blocks of 20 prime-probe trial pairs, in which stimulus duration was varied as described below.

On each prime trial, target and distractor letters were randomly selected, with the constraint that they not match. The target letter was flanked on both sides by the same distractor letter. The letter triplet was displayed for 100 or $300 \mathrm{msec}$, randomly selected, followed by the pattern mask. The pattern mask remained in view until the subject's response. If the subject responded correctly, a probe trial began immediately. If the subject responded incorrectly, the word ERROR was displayed for approximately $.5 \mathrm{sec}$, accompanied by a computer-generated tone. The monitor screen was then blanked for approximately $3 \mathrm{sec}$ before presentation of a new prime trial.
Probe target letters were randomly selected, with the constraint that they not match the prime target; distractors were randomly selected with the constraint that they not match the probe target, prime target, or prime distractor. The probe target therefore matched the prime distractor on one third of probe trials ("related" condition); on the remaining two thirds, prime and probe stimuli were unrelated. Probe triplets were presented for $0,33,100$, or $300 \mathrm{msec}$, randomly selected; the pattern mask then appeared and remained in view until the subject's response.

Error feedback on probe trials was determined by whether the subject's response corresponded to the randomly selected target, even on "catch" trials ( 0 -msec presentation). The monitor screen was blanked for approximately $3 \mathrm{sec}$ after a correct response, or after error feedback, before beginning the next prime trial.

\section{RESULTS}

Subjects made more errors on prime trials with 100 msec displays than on those with $300-\mathrm{msec}$ displays $\left[14.38 \%\right.$ versus $2.97 \% ; F(1,28)=15.95, M S_{\mathrm{e}}=118.40$, $p<.0005]$. Prime trial duration did not, however, have any significant effects on probe trial performance.

Table 1 displays the mean error rates for probe trial conditions, collapsed over prime trial durations. Error rates decreased as probe trial duration increased $[F(3,84)=$ $\left.349.72, M S_{\mathrm{e}}=386.14, p<.0001\right]$, and an overall negative priming effect was obtained $\left[F(1,28)=5.74, M S_{\mathrm{e}}=\right.$ $22.77, p<.05]$. In addition, the effect of relatedness interacted with duration $\left[F(3,84)=3.25, M S_{\mathrm{e}}=241.87\right.$, $p<.05$ ].

Because error variances varied greatly across probe durations, separate analyses were conducted for each probe duration. Negative priming was significant for both the $33-\mathrm{msec}$ and the $100-\mathrm{msec}$ durations [for $33 \mathrm{msec}, F(1,28)=5.01, M S_{\mathrm{e}}=456.07, p<.05$; for $\left.100 \mathrm{msec}, F(1,28)=8.03, M S_{\mathrm{e}}=121.26, p<.01\right]$. Despite the near-ceiling performance, negative priming also approached significance for the 300 -msec duration $\left[F(1,28)=3.06, M S_{\mathrm{e}}=28.76, p<.10\right]$. There was, however, no "negative priming" for the 0 -msec catch trials $[F(1,28)<1]$.

The catch trials permit an analysis of subjects' guessing strategies in the absence of any stimulus information. On the one third of catch trials nominally classified as "related," $30.91 \%$ of the responses corresponded to the preceding prime distractor (i.e., $100 \%-69.09 \%$ ). On the remaining two thirds nominally classified as "unrelated," subjects correctly guessed the computed but unseen target on $27.78 \%$ of trials $(100 \%-72.22 \%)$. Ergo, there is no indication of a response bias: Subjects guessed the preceding distractor at least as often as an unrelated letter alternative.

Table 1

Mean Error Percentages on Probe Trials, as a Function of Target Duration (in Milliseconds) and Relatedness to Prime Distractor

\begin{tabular}{|c|c|c|c|c|}
\hline \multirow[b]{2}{*}{ Probe Type } & \multicolumn{4}{|c|}{ Target Duration } \\
\hline & 0 & 33 & 100 & 300 \\
\hline Related & 69.09 & 63.00 & 13.86 & 2.86 \\
\hline Unrelated & 72.22 & 54.12 & 8.07 & 1.12 \\
\hline Negative priming & -3.13 & 8.88 & 5.79 & 1.74 \\
\hline
\end{tabular}


Prime and probe targets were never identical, and a response repetition was therefore necessarily an error. Although not directly recorded, the frequency of response repetitions on catch trials can be estimated from the guessing probabilities given above: If we assume that subjects guessed the preceding distractor on $30.91 \%$ of catch trials, and each of the two unrelated alternatives on $27.78 \%$ of catch trials, this leaves $13.53 \%$ of catch trials accounted for by response repetitions. Thus, response repetitions did occur, despite the error feedback provided even on catch trials. On the other hand, response repetitions occurred less often than the other possible guesses, indicating that subjects were sensitive, to some degree, to the sequential constraints.

\section{DISCUSSION}

Negative priming occurred for briefly displayed probe target letters, despite absence of pressure to make speeded responses and absence of any bias against guessing the prime trial distractor. The results indicate, therefore, that negative priming actually suppresses the availability of information regarding stimulus identity.

This conclusion is consistent with the speculation that distracting information is actively blocked from conscious awareness (Neill, $1989,1993)$. Related probe targets probably overcome this inhibition if presented at long durations; the targets become fully visible, even though their processing is delayed. The present results suggest that shorter duration targets may fail to overcome the inhibition, with the consequence that they are not consciously identified.

It is more difficult to reconcile this result with evidence that negative priming affects response selection (Neill, Valdes, \& Terry, 1992; Neill, Valdes \& Kennedy, 1994). Thus, negative priming effects may not be confined to only one stage of processing. It may also be noted that interactions with stimulus-response compatibility were obtained in a target localization task, rather than in an identification task like the present one. In the localization task, negative priming occurs when a defined target appears at a recently ignored location (Tipper, Brehaut, \& Driver, 1990). Some authors have argued that the mechanisms underlying negative priming of location and negative priming of identity are qualitatively different (Connelly \& Hasher, 1993; Park \& Kanwisher, 1994; Tipper \& McLaren, 1990).

In contrast to experiments investigating $R T$, the present experiment more clearly demonstrates that recognition of a recently ignored object is inhibited. It is, of course, possible that these results are restricted to specific parameters of the experiment-for example, a small set of frequently repeated letter stimuli. Whether the present results generalize to larger stimulus sets or other materials (e.g., words, pictures) and tasks (e.g., localization, matching) remains to be investigated. If these results are indeed generalizable, masked identification may provide a useful paradigm for studying negative priming in populations and task environments in which latency measurements are either unreliable or impractical.

\section{REFERENCES}

Connelly, S. L., \& HASher, L. (1993). Aging and the inhibition of spatial location. Journal of Experimental Psychology: Human Perception \& Performance, 19, 1238-1250.
Dalrymple-Alford, E. C., \& Budayr, B. (1966). Examination of some aspects of the Stroop color-word test. Perceptual \& Motor Skills, 23, 1211-1214.

Lowe, D. G. (1979). Strategies, context, and the mechanism of response inhibition. Memory \& Cognition, 7, 382-389.

NEILL, W. T. (1977). Inhibitory and facilitatory processes in selective attention. Journal of Experimental Psychology: Human Perception \& Performance, 3, 444-450.

NEILL, W. T. (1989). Ambiguity and context: An activation-suppression model. In D. S. Gorfein (Ed.), Resolving semantic ambiguity (pp. 63-83). New York: Springer-Verlag.

NEILL, W. T. (1993). Consciousness, not focal attention, is causally effective in human information processing: Commentary on Velmans (1991). Behavioral \& Brain Sciences, 16, 406-407.

NEILL, W. T., LISSNER, L. S., \& BECK, J. L. (1990). Negative priming in same-different matching: Further evidence for a central locus of inhibition. Perception \& Psychophysics, 48, 398-400.

Neill, W. T., Terr Y, K. M., \& VAldes, L. A. (1994). Negative priming without probe selection. Psychonomic Bulletin \& Review, 1, 119121.

Nell., W. T., Valdes, L. A., \& Kennedy, C. E. (1994, April). Negative priming: Effects of $S-R$ compatibility. Paper presented at the meeting of the Eastern Psychological Association, Providence, RI.

Neill, W. T., Valdes, L. A., \& Terry, K. M. (1992, November). Negative priming in target localization. Paper presented at the meeting of the Psychonomic Society, St. Louis.

Neill, W. T., Valdes, L. A., \& TeRry, K. M. (1994). Selective attention and the inhibitory control of cognition. In F. N. Dempster \& C. J. Brainerd (Eds.), Interference and inhibition in cognition (pp. 207-261). New York: Academic Press.

Neill, W. T., Valdes, L. A., Terry, K. M., \& Gorfein, D. S. (1992). Persistence of negative priming: II. Evidence for episodic trace retrieval. Journal of Experimental Psychology: Learning, Memory, \& Cognition, 18, 993-1000.

PARK, J., \& KANWISHER, N. (1994). Negative priming for spatial locations: Identity mismatching, not distractor inhibition. Journal of Experimental Psychology: Human Perception \& Performance, 20, 613-623.

STROOP, J. R. (1935). Studies of interference in serial verbal reactions. Journal of Experimental Psychology, 18, 643-662.

TIPPER, S. P. (1985). The negative priming effect: Inhibitory priming by ignored objects. Quarterly Journal of Experimental Psychology, 37A, 571-590.

TipPer, S. P., Brehaut, J. C., \& Driver, J. (1990). Selection of moving and static objects for the control of spatially directed action. Journal of Experimental Psychology: Human Perception \& Performance, 16, 492-504.

TiPPER, S. P., \& Driver, J. (1988). Negative priming between pictures and words in a selective attention task: Evidence for semantic processing of ignored stimuli. Memory \& Cognition, 16, 64-70.

TipPeR, S. P., MACQueen, G. M., \& Brehaut, J. C. (1988). Negative priming between response modalities: Evidence for the central locus of inhibition in selective attention. Perception \& Psychophysics, 43, 45-52.

TIPPER, S. P., \& McLaREN, J. (1990). Evidence for efficient visual selectivity in children. In J. T. Enns (Ed.), The development of attention: Research and theory (pp. 197-210). Amsterdam: Elsevier.

(Manuscript received April 8, 1994; revision accepted for publication May 11, 1994.) 